Southern Illinois University Edwardsville

SPARK

Library and Information Services Faculty

Research, Scholarship, and Creative Activity

Library and Information Services

$4-2014$

\title{
Implementing a 3D Printing Service in an Academic Library
}

Steven W. Pryor

Southern Illinois University Edwardsville, pryor.steven@gmail.com

Follow this and additional works at: https://spark.siue.edu/library_fac

Part of the Higher Education Commons, Higher Education Administration Commons, and the Library and Information Science Commons

\section{Recommended Citation}

Pryor, Steven W., "Implementing a 3D Printing Service in an Academic Library" (2014). Library and Information Services Faculty Research, Scholarship, and Creative Activity. 1.

https://spark.siue.edu/library_fac/1

This Article is brought to you for free and open access by the Library and Information Services at SPARK. It has been accepted for inclusion in Library and Information Services Faculty Research, Scholarship, and Creative Activity by an authorized administrator of SPARK. For more information, please contact magrase@siue.edu,tdvorak@siue.edu. 


\section{Implementing a 3D Printing Service in an Academic Library}

Steven Pryor, Director of Digital Initiatives and Technologies

Southern Illinois University Edwardsville

Shortened title: 3D Printing in an Academic Library

This manuscript has not been published elsewhere and has not been simultaneously submitted for publication elsewhere.

Abstract: Makerspaces and related concepts and technologies are currently the subject of much discussion in the library community, particularly among public libraries. One prominent technology often featured in makerspaces is three-dimensional (3D) printing. In this article the author describes a 3D printing service launched at Southern Illinois University Edwardsville's Lovejoy Library; the justification for providing the service in an academic library, equipment selection, procedures and workflow, and evaluation of the success of the service to date.

KEYWORDS makerspaces, three dimensional (3D) printing, fused deposition modeling, academic libraries, technology

Steven Pryor

Director of Digital Initiatives and Technologies

Library and Information Services

Southern Illinois University Edwardsville

Box 1063

Edwardsville, IL 62026

E-mail: stpryor@siue.edu

Received: October 2, 2013

Accepted: November 4, 2013 
Three dimensional (3D) printing is a technology by which a machine builds a physical object from a digital model. At the time of this article, the most common 3D printing technique is "fused deposition modeling," wherein the digital model is sliced into cross-sections by software, a raw material (usually plastic) is heated to a near-liquid state, extruded in a thin bead, and the cross-sections are deposited in layers by a computer-controlled nozzle. As these layers build upon one another, the melted material fuses to the previous layer and hardens, and a physical object resembling the digital model takes shape.

This technology has existed for decades (Thilmany, 2001; Flowers \& Moniz, 2002), but equipment was extremely expensive and thus generally limited to large corporate research, development, and rapid prototyping operations (Scalfani \& Sahib, 2013). Recently, the "maker" and open-source movements have taken on the concept and provided plans and software for hobbyists to build their own 3D printers inexpensively with readily available parts. This has drastically reduced the cost of the basic technology and made it affordable to individuals, small businesses, schools, and libraries. This paper describes the implementation of a 3D printing service at Southern Illinois University Edwardsville's Lovejoy Library.

\section{Literature Review}

"Makerspaces" in libraries are definitely a trending topic in library discussion and literature, but much of the attention in this area has focused on public libraries (Balas, 2012; Britton, 2012). Little has been written so far regarding the use of 3D printing technology in academic libraries. The University of Nevada Reno claimed in 2012 to be the first academic library in the United States to offer the technology "across the board" (Free, 2012). Until that time, it had been common for 3D printers to exist alongside other rapid prototyping machinery in engineering and other specialized college and university departments. By locating the service in the library, the tools are provided for all disciplines, and the potential is created for cross-discipline collaboration and learning (Chin, 2012). 
As this technology expands into more libraries, it is apparent that there are as many different service models emerging as there are libraries implementing the service. Scalfani and Sahib (2013) detail the University of Alabama's model for managing their library 3D printing service, which included creation of a "studio" space with specialized software and training and workshops on how to use the tools. Trained users can access and use the studio independently, and the service is provided free of charge, at least during the pilot phase of the project. The printer chosen for this setting was a BFB 3DTouch, a capable yet fairly low-end "hobbyist" printer, evolved from the open-source RepRap project (Bits from Bytes, 2012). The University of Nevada Reno chose to use both a 3DTouch as well as a higher end Statasys printer to address the expected needs of engineering users for precision and quality while minimizing the demand on staff to support and manage the printer (Chin, 2012). Groenendyk and Gallant (2013) describe the pilot project at Halifax's Dalhousie University Libraries, which utilizes the hobbyist grade Makerbot Replicator printer and manages the service as a mediated service rather than a hands-on studio experience, attributed largely to the complexities of processing files for printing and estimating and scheduling print times.

\section{Justification}

Libraries provide resources for not only for consuming information, but also for generating new information and research. In addition to books and academic journals, we traditionally provide creation tools such as computers, 2D printers, and copy machines. Sometimes the product of one's research may be a physical artifact such as a sculpture, a structural design, a prototype device, or a biological model. Southern Illinois University Edwardsville (SIUE) is home to many disciplines that can benefit directly from being exposed to this technology, including art, engineering, and science. Rather than a toy or distraction, this technology is being rapidly adopted in professional fields that our students will be entering after they leave the university. Aside from the obvious uses in manufacturing and engineering, applications such as printing custom prosthetics in medicine (Saldarriaga, Juan Felipe Isaza, 2011), 
visualizing geographic data (Groenendyk, 2013b), and replication of historical artifacts (Thilmany, 2012) are real world, multidisciplinary uses of this technology that can resonate with our faculty and students in our health sciences and humanities programs.

The recent decrease in the cost of 3D printing technology makes it feasible for libraries to begin providing this technology. As little as 10 years ago, a "mid-priced" FDM 3D printer from Stratasys cost “\$150,000 vs. $\$ 250,000$ for the high-end" system (Mid-priced FDM rapid prototyper uses ABS, PC., 2003). Today, do-it-yourself kits for hobbyist FDM machines can be found online for $\$ 500$ or less, and Stratasys machines with features comparable to 2003's "mid-priced" printer are now priced at less than $\$ 20,000$ (Castle Island Co., 2013).

\section{Execution}

In June, 2012, Lovejoy Library's Director of Digital Initiatives and Technologies was asked to provide requests for end-of-year funding. After an enthusiastic reception to the justification of 3D printing service in an academic library, the director investigated the services publicized by other libraries at the time, such as Dalhousie University Libraries and the Fayetteville Free Library.

The equipment considered ranged from a $\$ 500$ RepRap kit to the $\$ 20,000$ Stratasys uPrint. The university already owned two Stratasys uPrint 3D printers, one in an engineering lab and the other in the STEM Center of the East St. Louis Charter High School. Though we were familiar with the quality and relatively trouble-free operation as described by Chin (2012) in relation to the University of Nevada's choice of equipment, we were also familiar with the closed and proprietary nature of the system and the ongoing maintenance and materials costs associated with it. Because this purchase was to be a onetime expenditure, leased equipment and equipment necessitating a service contract for maintenance was effectively eliminated from consideration. With the combination of low cost (approximately $\$ 1,800$ ), open-source hardware heritage (meaning that the machine itself is completely user-serviceable and replacement parts and upgrades are readily available), a large user community for experience and 
support, and the option to receive it pre-assembled, the Makerbot Replicator was recommended for use in this project.

An anticipated problem with expanding 3D printing technology to disciplines other than engineering was that students in those disciplines may not have the CAD expertise required to create a digital model from scratch in software, though they may have the ability to create models in other forms such as clay, foam, or wood. One possible solution to this issue was proposed in the form a 3D scanner. Based largely on word-of-mouth and general media reputation at the time, the NextEngine 3D Scanner HD was proposed. In addition to its potential usefulness in the 3D printing service it was noted that Lovejoy Library maintains a collection physical artifacts (primarily Louis H. Sullivan architectural ornaments), presented online as a collection of photos of these artifacts which could eventually be updated to contain 3D models that would serve as a more useful online surrogate for researchers. The library ultimately purchased two Makerbot Replicators, a NextEngine 3D Scanner HD, and several spools of Makerbot filament (the printing material that is melted and turned into an object). Nearly 2 months were spent calibrating, testing, evaluating, tightening screws, tweaking software settings, and developing policies. Again, choosing a hobbyist grade printer such as the Makerbot means that although it is possible for a technically inclined user to self-maintain the equipment, the tweaking and experimentation required to accomplish and maintain good print quality is fairly substantial. Our experience, which seems to be echoed by Groenendyk and Gallant (2013), is that once the initial setup is complete and the printer is operating well, the ongoing maintenance is fairly trivial and requires little time investment.

The next consideration was to determine how the service would work. Upon becoming familiar with the printer and ReplicatorG, the software that processes the digital models to be printed, a couple of things became clear. One was that printing an object can take a long time. A 1-inch cube might take 15 minutes or less, but a 5 -inch skull might take 7 hours. It seemed that providing it as a walk-up, first- 
come first-served service like a typical printer might result in frustration as users waited for each other's lengthy print jobs, or if a user started a 3-hour print an hour before the building closed. Another issue was that ReplicatorG contains lots of settings and options, and it takes either experience or training to know when and how to adjust these settings to achieve optimal print quality. Overall, the process of ensuring a model is ready to print, processing it for the printer, and ensuring print quality was determined to be too complex for inexperienced users to be expected to perform themselves. It was determined that if users submitted files to library personnel experienced with the printer, it would be less time-intensive for those personnel to process and print the files than to train all interested students to do it themselves. Thus, we designed the workflow as a mediated service wherein we would receive 3D models via email or chat, process and provide an estimate of print time and cost, and send the file to the printer. Since much of the time involved in processing and printing files is simply waiting for the operation to finish, it does not take an unreasonable amount of work-time investment in general, perhaps 15 minutes per day of active involvement.

Lovejoy Library charges for the plastic material used, plus some extra for machine maintenance and to reprint failed prints (if an error, air bubble, temperature swing, or other problem causes an object to turn out poorly or be incomplete). This was originally estimated at $\$ 2$ per hour of print time, arrived at by weighing printed objects and dividing the time and weight into the known cost of $1 \mathrm{~kg}$ of plastic spool, and has since been lowered to $\$ 1$ per hour as the sample size of printed objects grew larger. An average object about 3 " -4 " on a side will usually take 2 to 3 hours to print and cost about $\$ 2.50$. Cost is mainly dependent on object size and shape complexity. 3D scanning services are currently performed by appointment and at no cost.

\section{Policies and Procedures}

The following set of policies was developed to guide the operation of the 3D printing service once it launched. 
- 3D Printing instructions and tutorials for users will be available at http://siue.libguides.com/3d.

- Cost: $\$ 1.00$ per hour of printing, to the nearest half-hour, as estimated by the printer control software. This charge accounts for plastic costs, machine wear, occasional print failures requiring reprints, and so on.

- Users are responsible for creating their own 3D models. Library staff may perform trivial repairs using automated software processes (checking for duplicate edges, unfilled holes, and so on), but staff cannot and will not assist in creating or editing designs. When a user has an object to 3D scan, library staff will perform the scanning and create a printable .stl file.

- Print requests will be submitted through the "File Upload" capability of Libraryh3lp -- in other words, while staff are available and logged into the $3 \mathrm{dPrint}$ chat queue. Staff will:

- Accept the file

- Process the file in the printer control software (ReplicatorG)

- Notify the user of errors or problems

- Give the user a cost estimate

- Schedule the job and give a pickup date, taking the user's name and email address

- Print requests are also accepted via email and will be processed as soon as possible after receipt.

- At or before the scheduled start time for a print job, staff will print the object, attach the user's information with the quoted cost ("Lovejoy Library 3D Printing Service Pickup Form"), and deliver the object to the circulation desk, where the user will pay for and pick up their item.

- Some objects (such as those with steep overhangs) require temporary support material to be printed. This material is easily removable; the user will be completely responsible for removing this material -- library staff will NOT remove support material.

- Items printed on the Makerbot Replicator may have small surface defects such as bumps or 
holes. These routine defects will not be cause for refund or lack of payment for the object. Also note that while the Replicator is very accurate, we will not guarantee any precise tolerances on fitting of multi-part objects.

- All submissions are subject to approval based on scheduling and availability. We reserve the right to decline any print request for any reason.

\section{Evaluation}

The service was launched at the Library and Information Services Open House on September 19, 2012. The printer was on display and printing example objects. The Director of Digital Initiatives was present to explain the technology to students and answer questions. It was a highly successful event in that hundreds of students saw the printer, asked questions, and shared their ideas. Other outreach efforts included working with the Dean of Library and Information Services to attend faculty meetings of each school to present the technology and make them aware of this new library service. The Director of Digital Initiatives was subsequently invited by faculty members to present to two class sessions to explain and promote the technology to their students. A LibGuide was created containing information, resources, and tutorials and linked prominently on the library's homepage and in handouts and promotional materials. After these efforts, web traffic to the service's LibGuide indicated interest (see

Figure 1), but actual print submissions were relatively few (see Figure 2). The first official print request was actually received on October 24, from a student in the School of Art \& Design wishing to scan and reproduce his original sculptures. Through the service's first year, we have processed 117 individual print requests from 30 separate users that include both students and faculty. Twelve of these 30 users have made repeat requests.

[place Figure 1 here]

[place Figure 2 here] 
The relatively high repeat user rate indicates a high level of satisfaction with the service among those who have used it (which is backed up, anecdotally, by our conversations with these users). The numbers themselves, however, are not necessarily impressive given the size of our potential user population (total enrollment approximately 14,000). The projects that we have produced for students and faculty have been exciting and often surprising in their ingenuity, so despite the low numbers we consider the service a success, albeit one with lots of room to grow.

We have some theories regarding why, despite the apparent interest in the technology and the service itself, the usage numbers are so low. As we originally suspected, and Groenendyk (2013a) notes, many users simply do not know how to create a 3D model or do not have access to software that allows them to do it. Unlike Groenendyk (2013a) reports at Dalhousie, however, very few (about 24\%) of the print requests received at Lovejoy Library are models downloaded from Internet sources. This would suggest that we could possibly feature and promote online 3D repositories (such as Makerbot's own Thingiverse.com) more prominently to increase awareness that the service can be used with ready-toprint models available for free download. We may also explore providing software within the library and teaching workshops on 3D modeling, perhaps in collaboration with other faculty who may already teach this topic in their curriculum. We do not think cost is generally a deterring factor, as only one user has ever declined a print after a cost estimate (which was for a large, complex print), and most users express happy surprise at receiving a cost estimate. Regardless, our primary reason for charging is simply to recover the cost of the plastic, and as such we have found over time that we can reduce the \$2 per hour charge closer to $\$ 1$. The other major hurdle we see, then, is that many students still may not see how the technology can help their scholarship or be used in their research. We will continue our outreach efforts to faculty and departments and attempt to inspire students with novel examples of how this technology can be used in their field of study and in their professional lives after graduation.

\section{Conclusion}


3D printing is a rapidly evolving and rapidly maturing technology, as low-cost devices vastly increase the user base to which it is available. There is currently much debate about whether these devices have a place in libraries, which is curious because there is little debate these days about the value of computers and laser printers in libraries. As technology shifts, so do libraries: for many years the technology of information distribution was text and paper, and that was reflected in the technology collected and provided by libraries. Technology now exists and is affordable to create and distribute information in new ways, and particularly for academic libraries 3D printing creates possibilities for teaching and research, as well as providing students familiarity with a technology that is affecting nearly every industry.

Our own experience providing the service at Lovejoy Library would appear to some to be a mixed bag at best. Usage numbers are admittedly low. The users who have used the service, however, tend to be excited about the possibilities that it opens for the work or research. From the art student excited about turning a delicate original piece into a durable representation for display and distribution, to the faculty member literally inventing a piece of lab equipment to accomplish an experiment, these projects have been fascinating examples of the creativity and productivity that occurs when tools are made available to all who might use them. The usage numbers can be increased, and we believe they will. It is clear from the literature so far that every library is different, and there is no single solution, service model, or workflow that is appropriate for every circumstance. A library looking to implement such a service should evaluate their circumstances and set their own metrics for success, and be prepared to accept that the technology and people's familiarity with it is still evolving. 


\section{References}

Balas, J. L. (2012). Do makerspaces add value to libraries? Computers in Libraries, 32(9), 33-33.

Bits from Bytes (2012). 3D touch 3d printer. Retrieved from

http://www.bitsfrombytes.com/content/3dtouch-3d-printer

Britton, L. (2012). The makings of maker spaces. Library Journal, 137(16), 20-23.

Castle Island Co. (2013). Comparison chart of all 3D printer choices for approximately $\$ 20,000$ or less. Retrieved September 29, 2013, from http://www.additive3d.com/3dpr cht.htm

Chin, Y. M. (August 7, 2012). U. Nevada library offers 3D printing across the board. Retrieved September 20, 2013, 2013, from http://lj.libraryjournal.com/2012/08/academic-libraries/u-nevada-library-offers3d-printing-across-the-board/

Colegrove, T. (2013). Editorial board thoughts: Libraries as makerspace? Information Technology \& Libraries, 32(1), 2-5.

Flowers, J. \& Moniz, M. (2002). Rapid prototyping in technology education. Technology Teacher, 62(3), 7-11.

Free, D. (2012). University of Nevada-Reno library offers 3-D printing. College \& Research Libraries News, 73(8), 455-455.

Fused deposition modeling builds functional medical instrument. (2004). Advanced Materials \& Processes, 162(5), 16-16.

Good, T. (2013). Three makerspace models that work. American Libraries, 44(1), 45-47.

Groenendyk, M. (2013a). A further investigation into 3D printing and 3D scanning at the Dalhousie University Libraries: A year long case study (http://www.carl-abrc.ca/uploads/Publications/2013-0426\%20Michael\%20Groenendyk\%20ENG.pdf ed.) Canadian Association of Research Libraries.

Groenendyk, M. (2013b). Emerging data visualization technologies for map and geography libraries: 3-D printing, holographic imaging, 3-D city models, and 3-D model-based animations. Journal of Map \& Geography Libraries, 9(3), 220-238. doi:10.1080/15420353.2013.821436

Groenendyk, M. \& Gallant, R. (2013). 3D printing and scanning at the Dalhousie University Libraries: A pilot project. Library Hi Tech, 31(1), 34-41. doi:10.1108/07378831311303912

Gutsche, B. (2013). Makerspaces in libraries: Patron's delight, staff's dread? Alki, 29(1), 28-30.

Hoy, M. B. (2013). 3D printing: Making things at the library. Medical Reference Services Quarterly, 32(1), 93-99. doi:10.1080/02763869.2013.749139 
Kaur, S. (2012). How is "Internet of the 3D printed products" going to affect our lives? IETE Technical Review, 29(5), 360-364. doi:10.4103/0256-4602.103164

Loertscher, D. V. (2012). Maker spaces and the learning commons. Teacher Librarian, 39(6), 45-46.

Mid-priced FDM rapid prototyper uses ABS, PC. (2003). Plastics Technology, 49(9), 37-37.

Murray, S. (2013). Turning students into engineers with 3D printing. Tech Directions, 73(1), 12-14.

Saldarriaga, J. F. I., Vélez, S. C., Posada, M. D. A., Henao, I. E. B., \& Valencia, M. E. C. (2011). Design and manufacturing of a custom skull implant. American Journal of Engineering \& Applied Sciences, 4(1), 169174.

Scalfani, V. F. \& Sahib, J. (2013). A model for managing 3D printing services in academic libraries. Issues in Science \& Technology Librarianship, (72), 1-1. doi:10.5062/F4XS5SB9

Thilmany, J. (2001). Printing in three dimensions. Mechanical Engineering, 123(5), 58.

Thilmany, J. (2012). History in 3-D. Mechanical Engineering, 134(4), 44-46. 


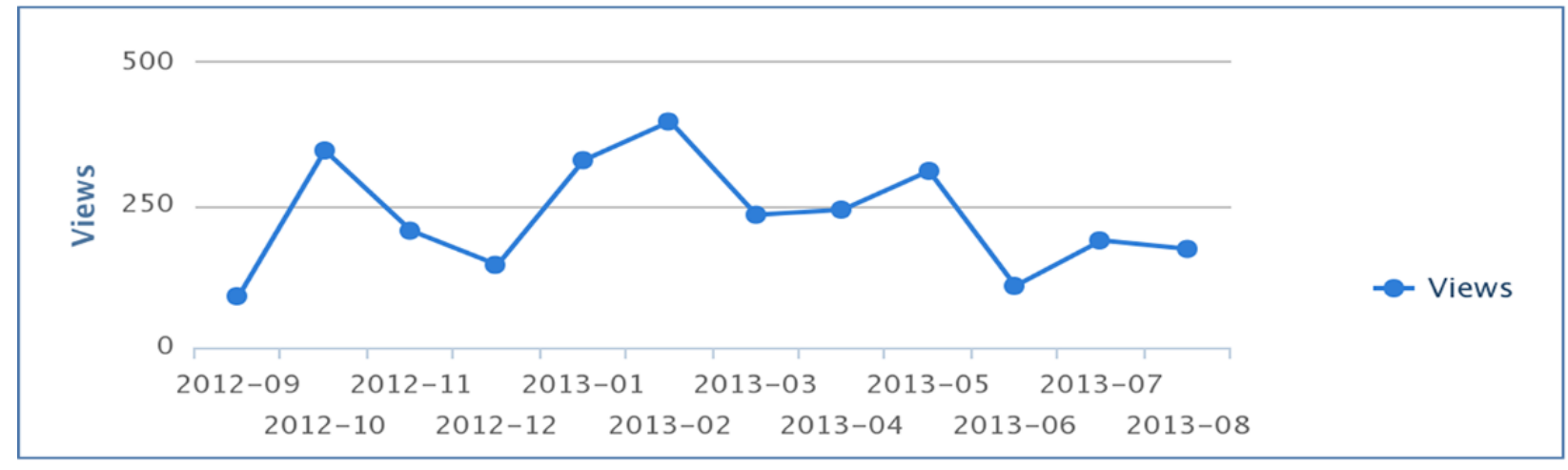

Figure 1: 3D Printing LibGuide monthly pageviews 


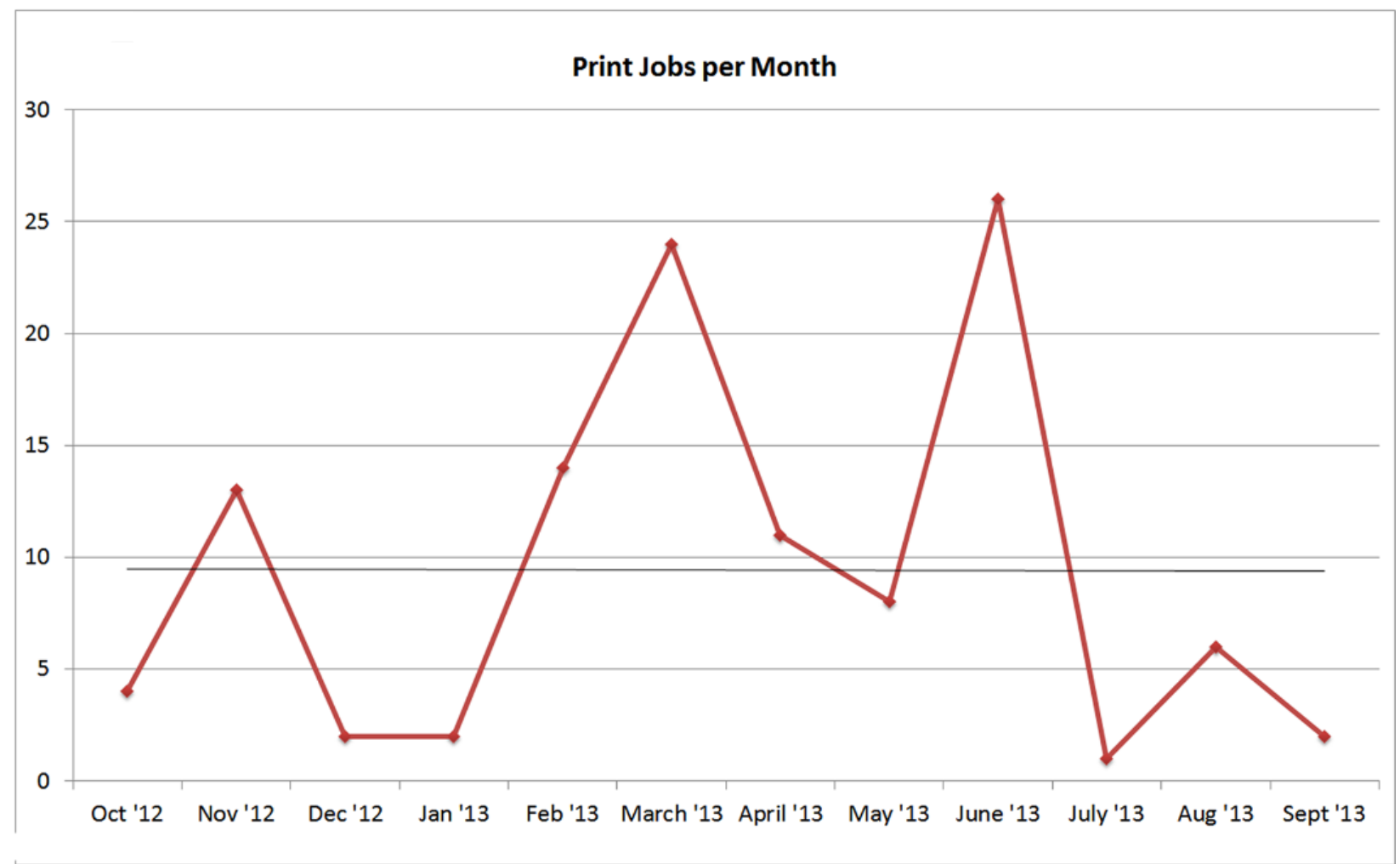

Figure 2: Print jobs per month 